\title{
Characteristics of Metal Reduction During Prereduction of Chromite types of Ore
}

\section{Vasilii Efimovich Roshchin and Anton Vasiliivich Roshchin}

South Ural State University (National Research University), 76, Lenin prospekt, Chelyabinsk, Russia, 454080

\section{Abstract}

Iron and chromium were reduced from chromium spinel at $1300^{\circ} \mathrm{C}$ and $1400^{\circ} \mathrm{C}$ during 1 and 4 hours. The reduction was carried out with carbon or $\mathrm{CO}$ gas in one experiment simultaneously for six samples of three different types of ore. It was established that under these conditions, the $\mathrm{CO}$ gas neither reduces chromium nor iron from complex chromium spinel, whereas solid carbon reduces iron and chromium completely. In the mixture of solid reagents at the initial stage of reduction with solid carbon, the carbide shell was formed on the surface of carbon and oxide, accurately reproducing the surface topography of the particles. The formation of the shell indicated a counter-

Corresponding Author: Vasilii Efimovich Roshchin roshchinve@susu.ru

Received: 5 February 2019 Accepted: 6 March 2019 Published: 17 March 2019

Publishing services provided by Knowledge E

(c) Vasilii Efimovich Roshchin and Anton Vasiliivich Roshchin. This article is distributed under the terms of the Creative Commons Attribution License, which permits unrestricted use and redistribution provided that the original author and source are credited.

Selection and Peer-review under the responsibility of the NIOKR-2018 Conference Committee.

\section{G OPEN ACCESS} transfer of the oxide substance to the surface of carbon and carbon substance to the surface of the oxide through the gas phase. The shell retarded and stopped the reduction process, however, when the shell substance was melted and drained, the reduction process continued. The same shell, but from the $\mathrm{Fe}-\mathrm{Cr}$ non-carbon alloy, was formed on the surface of the single spinel crystals interspersed in a large volume of magnesium-silicate matrix. The results of the experiments were explained from the standpoint of the theory of the electron reduction mechanism developed by the authors with the formation of plasma in the gas gaps and its participation in the contactless electron-ion exchange between solid reagents.

Keywords: metallization, ferrochrome, theory of reduction, low-temperature plasma, electron-ion exchange

\section{Introduction}

In chromium types of ore, iron and chromium are found in oxide spinels of the $\left(\mathrm{Me}^{2+}\right)$ $\left[\mathrm{Me}^{3+}\right]_{2} \mathrm{O}_{4}{ }^{2-}$ type along with cations of other metals, mostly magnesium and aluminum [1-3]. Due to the equality of charges and proximity of the ionic radii, the $\mathrm{Fe}^{2+}$ cations can unlimitedly mix with the $\mathrm{Mg}^{2+}$ cations, and the $\mathrm{Cr}^{3+}$ cations with the $\mathrm{Fe}^{3+}$ and $\mathrm{Al}^{3+}$ cations, respectively. Therefore, the composition of spinel in chromium ore in general form corresponds to the formula $\left(\mathrm{Mg}_{m}{ }^{2+}, \mathrm{Fe}_{n}{ }^{2+}\right)\left[\mathrm{Fe}_{x}{ }^{3+}, \mathrm{Al}_{y}{ }^{3+}, \mathrm{Cr}_{z}{ }^{3+}\right] \mathrm{O}_{4}{ }^{2-}$. In addition, in the spinel the substitutions of the type $2 \mathrm{Cr}^{3+} \rightarrow \mathrm{Mg}^{2+}+\mathrm{Si}^{4+}$ or $\mathrm{Cr}^{3+}+\mathrm{Al}^{3+} \rightarrow \mathrm{Mg}^{2+}$ 
$+\mathrm{Si}^{4+}$ are possible. Such a substitution is also possible with the $\mathrm{Ti}^{4+}$ cation, as well as dissolution of manganese, potassium and sodium cations in spinel $[4,5]$. Depending on the genesis of chromium ore, the composition of spinel can be quite complex with a wide range of concentrations of various cations. Thereby, in the production of carbon ferrochromium the cations of interest; iron and chromium, are in the same crystal lattice with other cations, including those which cannot be reduced under conditions of the metal production: magnesium, aluminum, silicon, titanium, potassium and sodium, occupying tetrahedral and octahedral sites in the most dense anion (oxygen) package. In addition, iron often presents in a certain amount in the crystalline lattice of silicate cementing phases. During solid-phase reduction in the upper zones of the ferroalloy furnace and prereduction outside the furnace, the goal is to extract iron and chromium cations from the complex chrome spinellid oxide and iron cations from the silicate phases.

The value of the solid-phase reduction processes increases due to expanding practice of prereduction, when the ore material is mixed with a solid reducing agent, heated to temperature of $1300 \ldots 1500^{\circ} \mathrm{C}$ and held for $2 \ldots 3$ hours. As a result, the reduction degree of iron reaches $90 \%$ and chromium $50 \%$, accordingly, that reduces the electricity consumption of ferroalloy furnace during smelting of ferrochrome [6]. In recent years the attempts have been made to use natural gas instead of solid reducing agents for prereduction of metals from chromite ore [7-9]. But at the same time, the solid pyrocarbon is also formed as a result of the methane pyrolysis, and it serves as a solid reducing agent as well $[7,8]$.

\section{Objectives and Experimental Methodology}

The research was aimed to clarify the mechanism of metal reduction by carbon and formation of carbides in complex oxides of solid chromium types of ore. At the same time, it was proceeded from the well-known position of physical chemistry, stating that it is necessary to find out "... the mechanism of the motion of reacting molecules and electrons which perform an act of the chemical reaction" [10].

TABLE 1: The composition of chromite ore, at. \%. (Source: The work of the authors.)

\begin{tabular}{l|c|c|c|c|c|c|c|}
\hline Material & $\mathrm{O}$ & $\mathrm{Mg}$ & $\mathrm{Al}$ & $\mathrm{Si}$ & $\mathrm{Cr}$ & $\mathrm{Fe}$ & $\mathrm{Cr} / \mathrm{Fe}$ \\
\hline ore 1 & 42.5 & 12.9 & 5.8 & - & 32.0 & 6.8 & 4.7 \\
\hline ore 2 & 60 & 9.4 & 6.4 & - & 19.0 & 5.2 & 3.6 \\
\hline dunite & 61 & 4.3 & 4.3 & 0.2 & 15.1 & 14.8 & $\sim 1.0$
\end{tabular}




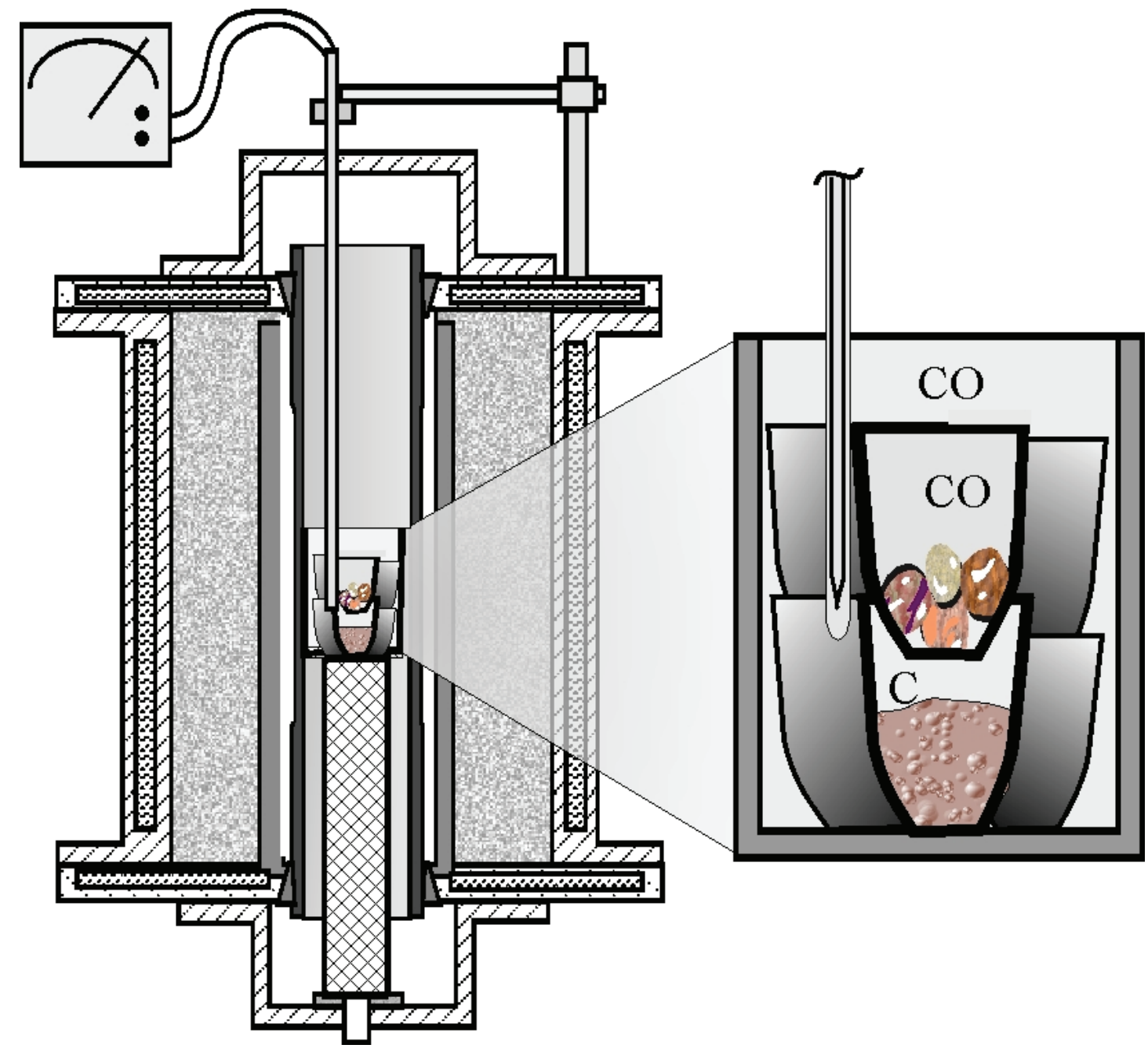

Figure 1: Experimental setup. The work of the authors.

To clarify the reduction mechanism, the conditions were created for the direct and indirect reduction of iron and chromium from natural complex oxides - the chromespinelid of the two types of chromite ore with different ratios of chromium and iron in spinel and spinel crystals embedded in a dunite magnesium silicate rock (see Table 1). The reduction experiments were carried out in a closed furnace with a graphite heating element (Figure 1), which ensured that the reduction atmosphere in the furnace was CO. 6 corundum crucibles with 3 oxide materials were installed inside the furnace; one sample of each material had contact with powder of a solid reducing agent (graphite), and another could only interact with $\mathrm{CO}$ gas. The furnace was heated to temperature of $1300^{\circ} \mathrm{C}$ or $1400^{\circ} \mathrm{C}$ and held for $1 . . .4$ hours.

The results of the experiments are presented in Figure 2. In the samples of both types of chromite ore reduced by $\mathrm{CO}$ atmosphere, iron was partially reduced only in the cementing silicate phase of the chromite crystals. At the same time, in a mixture with solid carbon, iron and chromium in the spinels of both types of chromite ore were 
completely reduced. A different ratio of chromium and iron contents in spinelid did not lead to any visible difference in the results of reduction.

It is worth to note formation of the shell on the surface of oxides and graphite in the mixture of solid chromite with solid carbon-containing material, which ideally repeats the surface of the particles (Figure 3). On the oxide surface, this is a mixture of carbides $\mathrm{Me}_{23} \mathrm{C}_{6}, \mathrm{Me}_{7} \mathrm{C}_{3}$ and $\mathrm{Me}_{3} \mathrm{C}_{2}$, whereas on the surface of graphite it is only carbide $\mathrm{Me}_{3} \mathrm{C}_{2}$. Such a shell cannot be the result of contact interaction of solid phases. Its formation indicates the transfer of carbon monoxide to the surface, and chromium and iron to the surface of graphite through the gas phase.

The formation of the closed shell of the reaction products on the surface of the reactants, firstly indicates the mutual transfer of one agent to the surface of another, and, secondly, it indicates the equal accessibility of this surface to both reactants. For their appearance, it is needed that carbon would transfer to the oxide surface, and the reducing metals to the surface of the reducing agent; the transfer to the all points of the surface should approximately occur at the same rate.
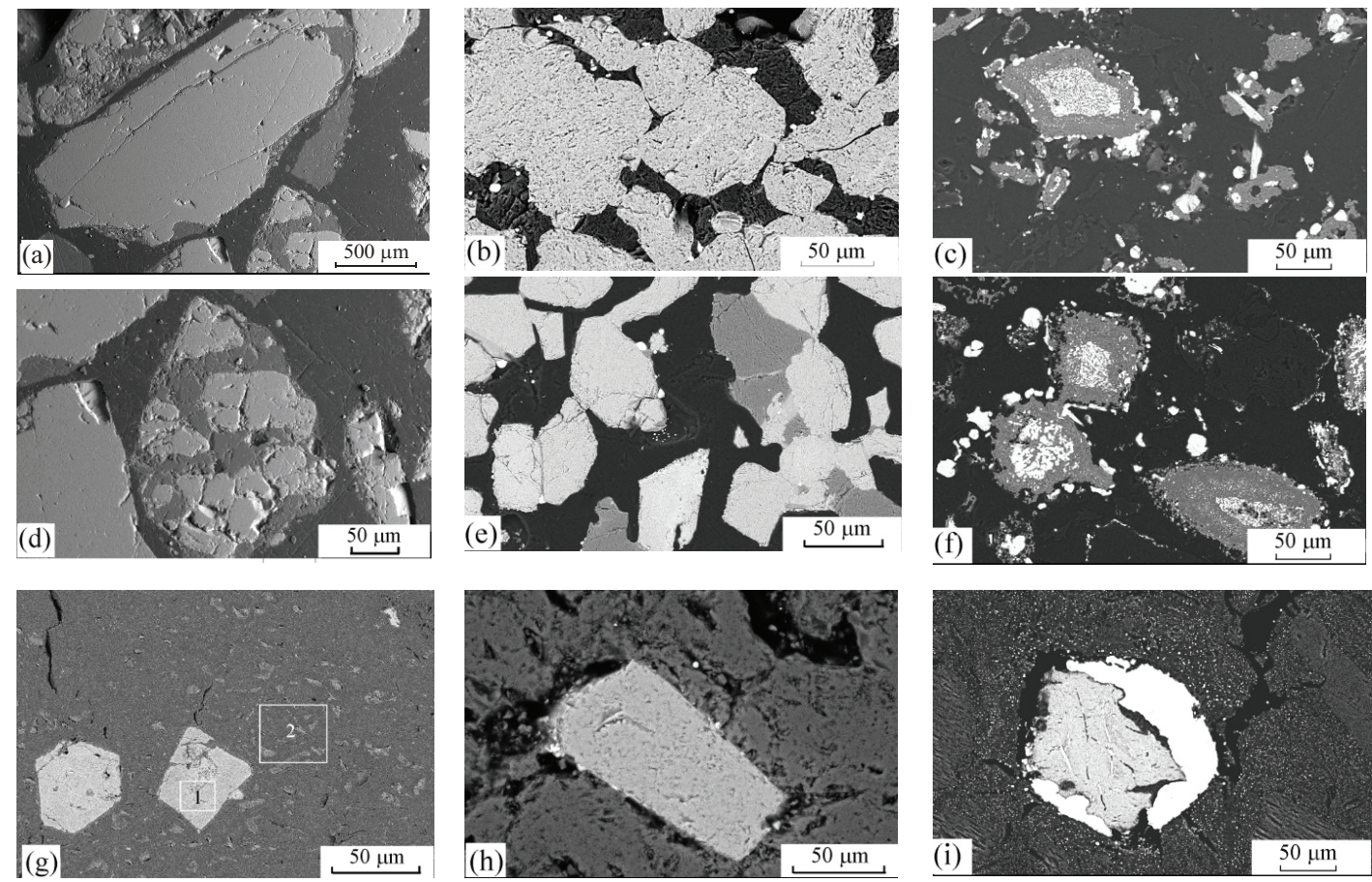

Figure 2: : The results of metallization of chrome-spinelid in the atmosphere of $\mathrm{CO}$ and in the mixture of $\mathrm{CO}$ with solid graphite at temperature of $1400^{\circ} \mathrm{C}$; time of reduction 4 hours: $(\mathrm{a}-\mathrm{c})$ - for ore 1 ; $(\mathrm{d}-\mathrm{f})$ - for ore 2 ; $(\mathrm{g}-\mathrm{i})$ for dunite. (a), (d), (g) - the initial state of spinelid; (b), (e), (h) - reduction in CO gas atmosphere; (c), (f), (i) - in the mixture of $\mathrm{CO}$ and graphite. The work of the authors.

In addition, the same shell, consisting of a carbon-free alloy of chromium with iron, also formed on the surface of chromite crystals interspersed in a solid silicate matrix 
of dunite in its mixture with a solid reducing agent (Figure 3(c)). Contrary, there were no signs of reduction of chromium or iron in the spinelid of dunite only exposed to the reducing atmosphere of $\mathrm{CO}$ gas (Figure $2(\mathrm{~h})$ ). Therefore, the reduction of chromium or iron by solid carbon in the impregnated spinelid crystals located far from the surface of possible carbon contact with oxide, especially the formation of the shell that accurately reproduces the surface of the disseminated crystal, cannot be explained by the participation of reducing gas $\mathrm{CO}$.


Figure 3: Shell of carbides on the surface of spinelide (a) and graphite (b) and the shell of a carbon-free Fe - Cr alloy on the surface of a spinelide crystal embedded in dunite (c). The work of the authors.

Thereby, the results of experiments do not correspond to the concepts of the mechanism of either direct or indirect reduction, but they fully confirm the electron theory of reduction developing by the authors [11-14].

The essence of this theory is in the fact that in any reduction reaction the reducing agent (solid carbon, gaseous $\mathrm{CO}$, or any other) does not interact with the oxide molecules of the metal being reduced (they are not in the oxide phase), but with anions of the oxygen-type crystal lattice of oxides. The products of this interaction $\mathrm{C}+\mathrm{O}^{2-}$ $=\mathrm{CO}+\mathrm{Va}^{2-}$ are gas molecules $(\mathrm{CO})$ and anion vacancies $\left(\mathrm{Va}^{2-}\right)$ in an oxide lattice. Since in any system the equality of positive and negative charges is always observed, if an anion vacancy is formed, then the two "free" electrons remain in it or appear that to compensate the absence of the anion. Due to the thermal motion of particles, the charged vacancies scatter in the oxide volume, merge at the sites of accumulations of cations with high electron affinity and disappear. The movement of the charged vacancies is identical with the movement of cations with a reduced charge or even atoms, but without the movement of the cations themselves. At the vacancy merger sites, the "excess" electrons transform the ionic bond of the oxide into a metallic ionic bond with formation of metallic phase.

Consequently, under these experimental conditions, the oxide surface should have been supplied through the gas phase; this is evidenced by the equal accessibility of the 
entire oxide surface, carbon and electrons. The contact of solid particles of carbon and oxide could provide them, but could not provide a uniform supply to the entire surface.

However, there is no need for direct contact of solid phases. This is due to the fact that a low-temperature plasma consisting of electrons, ions, molecules, and their associations is formed at the temperature of reduction near the surface of the solid phases [15]. The initial impulse to the plasma formation is thermionic emission of electrons from the carbon surface, quantitatively described by the Richardson-Dashman formula:

$$
I_{0}=A T^{2} \exp (-/ k T)
$$

where $A$ is a coefficient depending on the state of the surface, $\Phi$ is electron work function and $k$ is the Boltzmann constant [15-18]. The emitter of the free electrons is precisely carbon, as reducing agent has a weaker connection of external electrons with the atomic nucleus in comparison with oxides; the work function is less.

As a result of plasma formation, the charged particles, particularly $\mathrm{C}^{2+}$ and $\mathrm{O}^{2-}$, acquire the ability to interact at a considerable distance. Carbon is also transferred to the surface of the oxide and fragments of the crystal lattice of oxides to the surface of carbon particles through plasma (Figure 4), that leads to formation of carbide shell on the surface of the reactants.

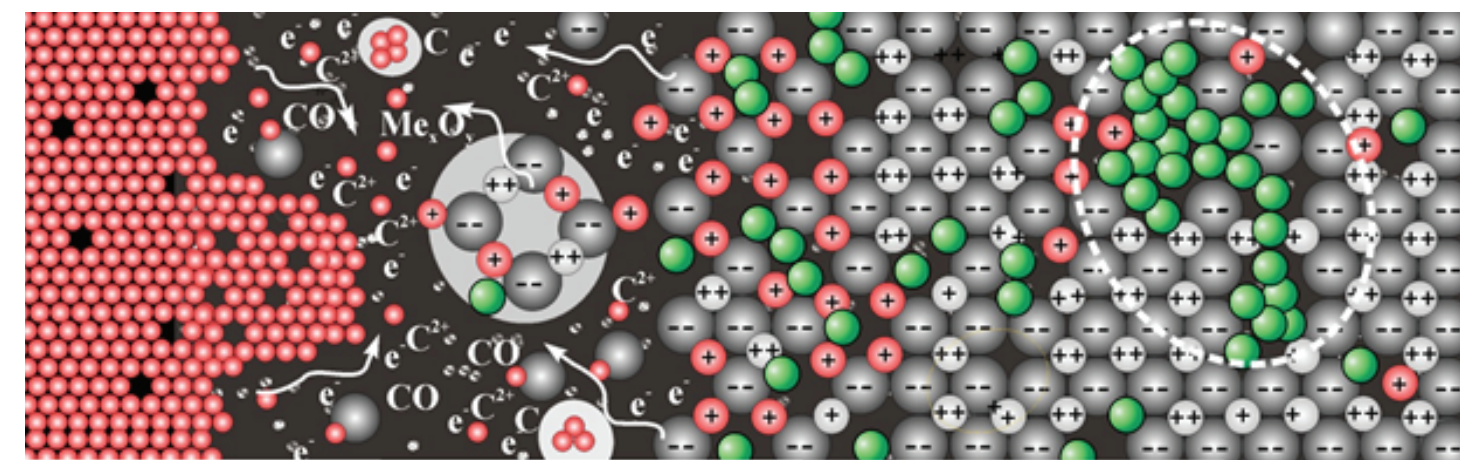

Figure 4: The electron-ion exchange scheme between a solid reducing agent and a solid oxide by means of plasma, propagation of a reduction process and formation of metal in the oxide volume. The work of the authors.

The formation of carbide shell worsens the surface of the reagents, retards and stops the reduction process. The measures to overcome the negative effect of carbide shell on the solid-phase reduction process have been studied earlier in other works [19-21].

In particular, the destruction of the shell is achieved by the temperature increase to the level when the mixture of carbides on the surface of the oxide is melted and collected in droplets [20]. The destruction of the shell makes it possible to reduce metal completely inside the solid residues of the oxide phase, as it can be seen in Figures 2(c) and (e). The retarding effect of the shell can also be eliminated by preventing their formation, 
for example, by deposition of oxide phase on the surface which does not contain the reducing cations [21]. At the same time, the reduction process does not slow down and even accelerates.

From the results mentioned above, it follows that the degree of metallization of the ore during prereduction is limited by formation of carbide shell on the surface of solid reagents; it is determined by the ratio of iron content in the cementing silicate phase, iron and chromium in spinel, and the ratio of the mass of the carbide shell and the residual mass of spinelid. If to accept all other things being equal, than lower the $\mathrm{Cr} / \mathrm{Fe}$ ratio in the ore is and then smaller the size of the ore particles, then higher the degree of metallization can be obtained.

\section{Conclusions}

1. In the complex chrome spinel at temperature of $1300 \ldots 1400{ }^{\circ} \mathrm{C}$, the $\mathrm{CO}$ gas does not reduce chromium and iron. The solid carbon under the same conditions reduces both iron and chromium.

2. The formation of carbide shell on the surface of carbon particles and oxide particles, ideally reproducing the surface topography of the particles, indicates a counter transfer of carbon to the surface of the oxide, and the oxide substance to the surface of carbon through the gas phase.

3. The formation of carbide shell retards and stops the reduction process. The degree of reduction, achieved in this case, is determined by the size of the particles and the thickness of the shell. The reduction continues after melting and draining of the shell material.

4. The reduction of iron and chromium with formation of similar shell, but consisting of carbon-free ferrochrome on spinel crystals interspersed in a massive block of magnesium-silicate rock confirms the electron-anion mechanism of propagation of the reduction process in the oxide phase.

5. The counter transport of matter of oxides and carbon through the gas phase, as well as the contactless electron-ion exchange between solid reagents in a mixture of solid particles, is explained by the formation and participation of ionized gas in the redox reactions, low-temperature plasma. 


\section{References}

[1] Gasik, M. I. and Lyakishev, N. P. Metallurgy of Chromium (Eliz, Moscow, 1999).

[2] Chernobrovin, V. P., Pashkeev, I. Yu., Mikhailov, G. G. et al. Theoretical Foundations of the Production of Carbon-Containing Ferrochrome from Ural Ores: Monograph (YuUrGU, Chelyabinsk, 2004).

[3] Grinenko, V. I., Polyakov, O. I., Gasik, M. I. et al. Chromium of Kazakhstan (Metallurgiya, Moscow, 2001).

[4] Sazonov, V. P. "Chromium in the hydrothermal process," in Proceedings of Ural Summer Mineralogical School, Yekaterinburg (UGTTA, Yekaterinburg, 1997), pp. 8186.

[5] Sizykh, A. I. and Bulanov, V. A. "Geochemistry of chromium in rock-forming minerals," in Proceedings of Ural Summer Mineralogical School, Yekaterinburg(UGTTA, Yekaterinburg, 1997), pp. 87-89.

[6] Cullough, S., Hockaday,S., Johnson C., Barcza N.A. Pre-Reduction and Smelting Characteristics of Kazakhstan Ore Samples// The Twelfth International Ferroalloys Congress Sustainable Future. Helsinki, Finland. 2010. - 249-262 pp.

[7] Anacleto, N. M., Solheim, I., Sørensen, B. et al. Reduction of chromium oxide and ore by methane-containing gas mixtures. Authors' Revised Draft Infacon XV: International Ferro-Alloys Congress, Southern African Institute of Mining and Metallurgy, Cape Town, 25-28 February 2018.

[8] Leikola, M., Taskinen P. and R.H. Eric. Reduction of Kemi chromite with methane. Authors' Revised Draft Infacon XV: International Ferro-Alloys Congress, Edited by R.T. Jones, P. den Hoed, \& M.W. Erwee, Southern African Institute of Mining and Metallurgy, Cape Town, 25-28 February 2018.

[9] Sokhanvaran, S., Paktunc, D. and A. Barnes. $\mathrm{NaOH}-a$ ssisted direct reduction of Ring of Fire chromite ores, and the associated implications for processing Authors' Revised Draft Infacon XV: International Ferro-Alloys Congress, Edited by R.T. Jones, P. den Hoed, \& M.W. Erwee, Southern African Institute of Mining and Metallurgy, Cape Town, 25-28 February 2018.

[10] Zhukhovitskii A. A. and Shvartsman L. A., Physical Chemistry (Metallurgiya, Moscow, 1968).

[11] Roshchin V.E. and Roshchin A.V. Selective Reduction of Metals in the Lattice of a Complex Oxide. Russian Metallurgy (Metally), 2013, No. 3, pp. 169-175. 
[12] Roshin V.E. and Roshin A.V. Selective extraction of metals from complex ores. Proceeding of the thirteenth international ferroalloys congress. INFACON XII. Kasakhstan, Almaty. June 9-12 2013. Vol. 2. pp. 685-695.

[13] Roshchin V.E. and Roshchin A.V. Selective Reduction of Metals in the Crystal Lattice of Complex Oxides: Physical Principles. Steel in Translation, 2013, Vol. 43, No. 5, pp. 278-287.

[14] Roshchin V.E. and Roshchin A.V. Physics of the Solid Phase Oxidation and Reduction of Metals. Russian Metallurgy (Metally), Vol. 2015, No. 5, pp. 354-359.

[15] Fizicheskij ehnciklopedicheskij slovar'. - M.: Sov. Ehnciklopediya, 1984. - 944 s.

[16] Lauton Dzh. and Vajnberg F. Termoehlektronnaya ehmissiya na metallah. - M.: Nauka, 1984. - $353 \mathrm{~s}$.

[17] Hering K. and Nikol's M. Termoehlektronnaya ehmissiya. - M.: Izdatel'stvo inostrannoj li-teratury, 1950. - $196 \mathrm{~s}$.

[18] Sisoyan, G.A. Ehlektricheskaya duga v ehlektricheskoj pechi. - M.: Metallurgizdat, 1961. - $414 \mathrm{~s}$.

[19] Roshchin, V. E., Roshchin, A. V. and Akhmetov, K. T. Mechanism and Sequence of the Metal Reduction in the Lattice of Chromospinelides. Russian Metallurgy (Metally) 2014, No. 3, pp. 173-178.

[20] Roshchin, V. E., Roshchin A. V. and Ahmetov K. T. Formirovanie metallicheskoj i karbidnyh faz pri poluchenii uglerodistogo ferrohroma: teoriya i ehksperiment. Problemy chernoj metallurgii i materialovedeniya. 2015, № 1. pp. 5-18.

[21] Roshchin, V. E., Roshchin, A. V., Akhmetov, K. T and Salikhov, S. P. Role of a Silicate Phase in the Reduction of Iron and Chromium and Their Oxidation with Carbide Formation during the Manufacture of Carbon Ferrochrome. Russian Metallurgy (Metally). Vol. 2016. No. 11. 1092-1099. 